\title{
The Effects of Commercialization Capability in Small and Medium-sized Businesses on Business Performances: Focused on Moderating Effects of Open Innovation
}

\author{
Joung-Hae Seo ${ }^{1}$, Jin-Ok Kim ${ }^{1} \&$ Woo-Seok Choi $^{1}$ \\ ${ }^{1}$ School of Business, Kyungpook National University, Daegu, Republic of Korea \\ Correspondence: Woo-Seok Choi, School of Business, Kyungpook National University, Daegu, Republic of Korea. \\ E-mail: wschoi@knu.ac.kr
}

Received: April 27, 2015

Accepted: May 11, 2015

Online Published: May 14, 2015

doi:10.5430/jms.v6n2p70

URL: http://dx.doi.org/10.5430/jms.v6n2p70

\begin{abstract}
This study aims to set the effects of technology commercializing capabilities (Acquisition / Internalization, market-oriented innovation, and exploitational innovation) on business performances (financial performance, non-financial performance, and innovational performance) as a primary model; examine the moderating effects of open innovation; build up the foundation to promote small and medium enterprises located in industrial complexes in Daegu; and lay groundwork for regional industrial strategies and national policy projects. We examined the relations between variables by conducting correlation measurement with only those variables that went through the above process. And hierarchical regression analysis was done to confirm our research model and hypothesis test.

The empirical analysis results of the research are as follows: First, we found that acquisition/internalization affected greatgly the firm's financial performance and innovation performance (the speed of commercialization, the number of new product developments). Second, technological exploitation has positive effects on on their financial performance and innovation performance (the speed of commercialization, and the number of new product developments). Third, market exploitation also influenced strongly financial and innovative performances. This is because small and medium-sized companies in Korea produce and deliver products that higher level companies order rather than they develop their own products and improve the management performance by selling them to the market. Fourth, small and medium-sized firms seek to overcome the drawbacks coming from geographic proximity by means of open innovation during the process of commercializing the goods with their transferred techniques.
\end{abstract}

Keywords: commercialization, acquisition/internalization, technological exploitation, market exploitation, open innovation

\section{Introduction}

\subsection{Research Background and Purpose}

As technology and knowledge have come to the fore as core competences for businesses thanks to industrial structure improvement, businesses not only believe that their competitive edge is from using and applying core technology, but seek to maximize their performances through exploiting the existing technology as well.

Due to the dawning of the era of the information and communication industry, firms, which plan to break into new markets and establish de facto standard in the industry, have increasingly thought of technical development both as a source of a competitive advantage and as an optimal strategy to make firms exist in the long term. Therefore, they are focusing to commercializing R\&D and its output.

Such commercializing process generally includes technical development and commercialization, but small and medium-sized firms hardly attempt to develop their own technology because of time and material needed. Accordingly small and medium-sized firms are concentrating on open innovation, a new R\&D style to increase efficiency and performance of R\&D investment. Especially for Korean businesses, commercialization achievement by R\&D investment is rather poor. And although they reached the stage of creating new technology and markets, it is practically impossible for them to cover immense expenses. So to develop new technology and products rapidly and to improve efficiency of technical development, small and medium-sized firms aim to improve their capabilities with 
the help of a new paradigm of open innovation.

This study aims to set the effects of technology commercializing capabilities (Acquisition / Internalization, market-oriented innovation, and exploitational innovation) on business performances (financial performance, non-financial performance, and innovational performance) as a primary model; examine the moderating effects of open innovation; build up the foundation to promote small and medium enterprises located in industrial complexes in Daegu; and lay groundwork for regional industrial strategies and national policy projects.

\section{Theoretical Background}

\subsection{The Concept of Technology Commercialization}

K. Chung (2009) states that the scope of commercialization includes all of the processes of ripening ideas elicited from research and development, technical development through ripened ideas, prototype process and new process development (including improving the existing process) using developed technologies, and sales and marketing by mass-producing new products.

Kukubu (2001) gives attention to $\mathrm{R} \& \mathrm{D}$ which is prerequisite to technology commercialization and explains the commercialization process, focusing on the points over decision-making process from the basic stage to draw up ideas to the stage of the manufacturing process. In Kukubu's study, research direction is decided after conducting conformity assessment just after each stage, when technology transfer is decided. This indicates that commcialization capability is the important element in the reinforcement of exploitational innovation capability for R\&D through transferred technology and in marketing innovation performance through market exploitation. Y. Lee (2004) presents a model biased toward commercializing after R\&D. He regards day care and its industrialization as technical exploitation and the items of prototype manufacture and engineering, plant location decisions and mass production, and marketing and diffuse enlargement as market exploitation ability. However, such studies presuppose the self-developed commercializing process, and are not sufficient to explain the introduction of technology from external firms, universities, or public institutions.

For commercialization with its own technical development and introduced technology, it is important to use the developed technology, maximize its value through market exploitation ability, and achieve its commercial goal (Frank Moulaert et al., 2003). The outcome of technology transfer depends on how an innovator of technology digests and absorbs the introduced one, and acquisition of technology trend information and willingness to get technological innovation (supports from top management) influence the outcome of technology transfer (Evan \& Olk, 1992; Spann et al., 1993).

Zahra \& Bogner (2000) emphasize the importance of producing ability regarding business performances. They reveal that the higher producing ability is, the more sales increase, and the higher producing ability, the higher the innovation of the product gets. Producing ability means its own ability to sustain the competitive edge within a company which its competitors cannot defeat. Not only does the company high in producing capability raise the speed of commercialization in the rapidly changing markets, but can reduce risks in market circumstances which the company faces, by improving the existing products and reducing switching costs into another market.

Griffin \& Hauser (1996) highlight the importance of marketing ability as the driving force of technological commercialization. They also claim that strong marketing ability provide R\&D with higher quality and information, and the interaction between marketing and R\&D increases business performances more than individual effects do. This marketing ability stresses improving the relationship with customers, leveraging technology and marketing, reading markets to pursuit innovation, getting market-oriented vision and value. Especially, they find that marketing ability has the greatest impact on the innovative output of technology-based firms, and they present that the ability to maintain innovation ability and the ability to industrialize innovation (creating customer-oriented products) are very critical for those firms in the high-tech market.

Previous studies on technology commercialization states the importance of technological commercializing ability, and so it is expected that the capability of technology commercialization affects performances of firms (D. Lee \& R. Chung, 2010).

\subsection{Open Innovation}

Radical changes in technology and market environment such as lack of R\&D human resources, enormous capital costs due to increase of R\&D scale, shortened product life cycle, reduced market entry speed, market access, and opportunity creation made it important to internally absorb the technology from the external source by building up technology innovation network. That is why a new paradigm of open innovation appeared to overcome the 
limitations of the previous closed innovation.

Chesbrough (2004) claims that to cope with the changing environment, firms should open their own technical innovation processes, vary the sources of innovation by making use of innovative ideas and technology from external sources, and transfer internally developed technology into outside, by which they should switch over to a system to raise revenue.

This concept is the one that emphasizes cooperation, network, and opening, and it is similar with the existing cooperative network. However, it is the concept that highlights the role of taking in externally-originated technology internally in various ways as well as the network relationship itself (Chesbrough, 2003).

\section{Research Model and Hypotheses}

\subsection{Research Model}

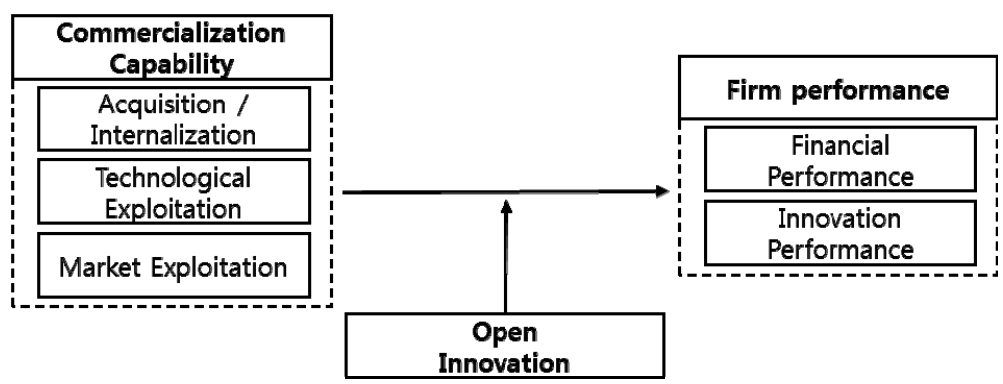

\subsection{Hypotheses}

We intend to establish our hypotheses based on the following: in the innovator's viewpoint, commercializing the introduced technology is the process to learn, use, produce, and market techniques acquired by transfer of technology developed outside, not by self-developed technology; it makes the firm not only deal with uncertain market environment flexibly, but save the firm money on technical development; and it can maximize performance by investing intensively depending on the firm's situation. Moreover, we are to examine the moderating effects of open innovation to supplement the geological limitations of industrial complexes and clusters.

\subsubsection{Relations between Acquisition / Internalization and Firm Performance}

To enhance firm performance and seek the interests, you should transform your firm from a technology-based firm into the firm that can create the newer technological capability and improve it based on explicit and implicit resources, rather than a firm that instruct only source technology by just receiving necessary techniques (Chen \& Qu, 2003).

In the study of Schroederetal (2002), which examined the manufacturer's capability and resource role, it appeared that competitive edge in manufacturing was influenced by proper processes and equipment and external and internal learning in the firm plays a critical role. Schroederetal (2002) also claims that external and internal learning of human resources, namely a firm's internal resource, has great effects on firm performances, as capability and resource cannot be copied and replaced in manufacturing.

From the innovator's position, technological learning of transferred techniques is to acquire technical know-how and technology and thus to reinforce the present one into higher-level technology or technical capability. It means that once you acquire technology, then you build up new technology and technical capability, and thereby firm capability becomes improved and firm performance increases.

H1 Acquisition/Internalization capability of the technique innovator will have a positive effect on firm performance.

H1-1 Acquisition/Internalization capability of the technique innovator will have a positive effect on financial performance.

H1-2 Acquisition/Internalization capability of the technique innovator will have a positive effect on innovation performance.

3.2.2 Relations between Technological Exploitation and Firm Performance

In order for an organization to be competitive and maintain its competitive advantage, it is important to improve and 
maintain its performance based on core competence which is suitable for the current market environment. However, it is also very important to find new capabilities of the work force and prepare for the future so as to maintain the competitive advantage and survive in the rapidly changing future market.

He \& Wong (2004) conducted the empirical study on 206 manufacturing firms in Singapore and Malaysia, and found that exploitational innovation activities had significant effects on the rate of sales increase, and exploitational innovation influenced positively $(+)$ both product innovation and process innovation.

S. Ha (2007) indicates that the outcome of exploitational innovation activities is prominently featured in process innovations which solve problems of the existing manufacturing process or upgrade the function or quality of the existing products. And he also maintains that small and medium-sized firms can adopt innovation strategies targeting product innovation such as performance or quality improvement of the existing goods.

In addition, small and medium-sized firms that focus on efficiently using the existing techniques prefer activity alternatives which have higher concreteness and certainty; repetitively pursue additional research and development activities that guarantee short-term results for environmental uncertainty; and concentrate on implementing exploitational innovation as uncertain costs occur in exploratory innovation strategies (Levinthal \& March, 1993)

$\mathrm{H} 2$ Technological exploitation of introduced technology will have a positive effect on firm performance.

H2-1 Technological exploitation of introduced technology will have a positive effect on financial performance.

H2-2 Technological exploitation of introduced technology will have a positive effect on innovation performance.

\subsubsection{Relations between Market Exploitation Capability and Firm Performance}

Zahra \& Bogner (2000) explain that in terms of firm performance, the higher manufacturing capability gets, the higher performance becomes. They also say that product innovativeness, frequent product improvement, active use of outside technologies all have significant influence on sales growth.

Manufacturing capability means having the ability of competitive advantage which competitors cannot challenge. A firm high in manufacturing capability can reduce the commercializing speed in the rapidly changing market and can reduce risks regarding improvement of the existing goods and switching costs into another market.

Production capability as well as manufacturing capability is one of the elements that affect business performances, and is the one that cannot be imitated. As production capability gets enhanced more, you can get higher performance in production and process of goods, and also achieve the goals in terms of manufacture such as quality, flexibility, prices, and due date (Hamel \& Praharad, 1990)

Griffin \& Hauser (1996) claims it is marketing capability that is remarkably critical in R\&D performance of a firm. They maintain that strong marketing capability offers better quality and information, and the interaction between marketing and R\&D increase firm performances more than individual effects do.

To summarize previous studies, obtaining a lot of superior technology is critical for a firm considering technological aspects, but the firm should strengthen manufacturing capability, production capability, and marketing capability of relevant techniques so that the outcomes of $\mathrm{R} \& \mathrm{D}$ can proceed to the market as competitive goods. It depends on technology commercialization to enter the target market with success, be flexible in responding by pursuing goods and strategy which are different from those of competitors, and so increase business performance.

H3 Market exploitation of introduced technology will have a positive effect on firm performance.

H3-1 Market exploitation of introduced technology will have a positive effect on financial performance.

H3-2 Market exploitation of introduced technology will have a positive effect on innovation performance.

\subsubsection{Relations between Open Innovation and Firm Performance}

Laurson \& Salter (2006) developed the notions of breath and depth as components of openness for external search strategies of each firm. We intend to measure open technological innovation using their notions in this research. In their study, as open innovation gets wider and deeper in width and depth, it affects positively business performance (the part that the world's first developed product contributes to sales, the part that the firm's first developed product contributes to sales, and the part that the upgraded product contributes to sales). Furthermore, in the study of J. Yun \& M. Choi (2008), the extension research of Laurson \& Salter's, they identify that the larger the extent (width and depth) of open technological innovation, the more the firm's innovation performance (the number of launching new products annually).

A firm cannot meet all the theoretical and technical requirements necessary for innovation only with its own internal 
capability. Hoffman (1998) conducted a study of small and medium-sized firms and revealed that firms not only innovated in a formal way but made good use of networks with the outside. It is also insisted that a firm utilize external techniques and knowledge effectively through technology development and active technical cooperation with outside firms or organizations (Lee, 1995). Therefore, these activities allow firm to access to potential information, resources, market, and technology, and help them to achieve their goals like technology development, cost saving, and market expansion (Gulati et al., 2000)

H 4 Open Innovation moderates the effects of introduced technology commercializing capability on fir performancein the positive manner.

H 4-1 Open Innovation moderates the effects of Acquisition / Internalization on financial performance in the positive effect.

H 4-2 Open Innovation moderates the effects of technological exploitation on financial performance in the positive effect.

H 4-3 Open Innovation moderates the effects of market exploitation on financial performance in the positive effect.

H 5 Open Innovation moderates the effects of introduced technology commercializing capability on innovation performance in the positive effect.

H 5-1. Open Innovation moderates the effects of Acquisition / Internalization on innovation performance in the positive effect.

H 5-2 Open Innovation moderates the effects of technological exploitation on innovation performance in the positive effect.

H 5-3 Open Innovation moderates the effects of market exploitation on innovation performance in the positive effect.

\section{Research Methods}

\subsection{Operational Definition and Measurement of Variables}

This research defines Acquisition / Internalization as "the process to acquire, learn, and digest transferred technology based on one's own situation" (Dyer \& Hatch, 2006), and performed measurement by dividing it into "technology related to product development, information technology of production and process, information and technology of general technology trend, information and technology of market trend, and general information and knowledge of customers".

Besides, to distinguish learning from Acquisition / Internalization, we divided and measured the degrees of learning transferred technology and digesting it properly according to technology related to product development, information technology of production and process, information and technology of general technology trend, information and technology of market trend, and general information and knowledge of customers, which lead to strengthening the logic of Acquisition / Internalization.

Variables of technological exploitation is defined as "a series of processes for transferred technology to go through the stage of Acquisition / Internalization and then through the stage of modification and convergence, and then to produce products similar or related to transferred technology". Absorptive capability from Jansen et al. (2005) and Lichtenthaler (2009) and questions from He \& Wong (2004) were revised and modified in accordance with this research and then measured.

Technological exploitation was classified under manufacturing capability, production capability, and marketing ability, based on the study of K. Kim et al. (1991). Among them, manufacturing capability of technology was particularly based on the study of Yap \& Souder (1994). Considering production) capability of technology, the measure was adopted based on the study of Yam et al. (2004). In terms of market exploitation both the measure of marketing effectiveness and the parts which share in common with the those studies of Yam et al, (1994) and Yap \& Souder (1994) were adopted and used.

Business performance is defined as "financial outcomes derived from acquisition/internalization, technological exploitation, market exploitation based on the transferred technology". "The speed of technology commercialization" was measured with five-point scale (Zahara \& Nielsen, 2002), and financial performance was measured by "total average of sales of technologically commercialized products for the last five years.

Open innovation is defined as "knowledge or ideas are delivered from the outside to the inside of a firm, and delivered from the inside to the outside of the firm", and we measured "the frequency that ideas come from the 
outside of a firm to the inside".

Regarding firm size, we selected a sample by narrowing it down to small and medium-sized firms, and controlled it to exclude influences on the number of employees, the firm size, the industrial scale, the industrial maturity, and the degree of competition.

\subsection{Data Collection and Analysis Method}

\subsubsection{Data Collection}

We conducted the survey to derive the factors affecting performances of small and medium-sized firms in processing transferred technology commercialization, targeting small and medium-sized firms which belong to the machine parts industry and the information and communication industry that received technology transfer. To increase the reliability of our survey, we targeted firms, located not only in Daegu and Kyungbuk area but also throughout the country, which had performed technology transfer and open innovation. In addition, we visit the firms in person and surveyed them to increase the response rate, while we notified the firms in other areas of our survey questions over the phone in advance and then performed our survey using self-legislation period via e-mail because we could not visit them in person.

\subsubsection{Analysis Method}

SPSS 18.0 was used for statistical analysis. General status of firms went through descriptive statistics, and reliability was verified using cronbach's $\alpha$ coefficient to assess internal consistency among items. During this process, the level of analysis for cronbach's $\alpha$ should be over .60 in terms of an organization or a group, and so we removed the items that had the level below .60. Exploratory factor analysis was done first and then confirmatory factor analysis was conducted to analyze unidimensionality and validity for variables.

We examined the relations between variables by conducting correlation measurement with only those variables that went through the above process. And hierarchical regression analysis was done to confirm our research model and hypothesis test.

\subsubsection{Common Method Variance Verification}

As every single respondent filled out the survey about all the variables of our research and collected responses were analyzed statistically, there was a possibility of common method bias, which was discussed by Podsakoff \& Oragan (1986), and so Harman's one factor test was executed. The results of the test showed that all eigen values were over 1.

\section{Research Results}

\subsection{Correlations}

Considering the correlations between variables, all independent variables of Acquisition / Internalization, technological exploitation, and market exploitation factors appeared to have positive $(+)$ correlations with management performance at $\mathrm{p}<.01$. And moderating variables of open innovation and technical characteristic factors also had positive $(+)$ correlations with management performance at $\mathrm{p}<.01$.

Table 1. Summary statistics and correlation matrix

\begin{tabular}{|c|c|c|c|c|c|c|c|c|}
\hline & M & SD & $\mathrm{FP}$ & IP & $\mathrm{A} / \mathrm{I}$ & $\mathrm{TE}$ & $\mathrm{ME}$ & OI \\
\hline Financial Performance (FP) & 3.14 & .653 & 1 & & & & & \\
\hline Innovation Performance (IP) & 3.28 & 692 & $.998 * * *$ & 1 & & & & \\
\hline Acquision/Internalization (A/I) & 3.10 & .730 & $.816^{* * *}$ & $.805^{* * *}$ & 1 & & & \\
\hline Technological Exploitation (TE) & 3.20 & .932 & $.864 * * *$ & $.859 * * *$ & $.746^{* * *}$ & 1 & & \\
\hline Market Exploitation (ME) & 3.13 & .745 & $.821 * * *$ & $.827 * * *$ & $.596 * * *$ & $.617 * * *$ & 1 & \\
\hline Open Innovation (OI) & 310 & .750 & $.854 * * *$ & $.589 * * *$ & $.544 * * *$ & $.621 * * *$ & $.948 * * *$ & 1 \\
\hline $\mathrm{N}=69, \mathrm{P}^{*}<.1, \mathrm{P}^{* *}<.5, \mathrm{P}^{* * *} .01$ & & & & & & & & \\
\hline
\end{tabular}




\subsection{Hierarchical Regression Analysis}

Hierarchical regression analysis was performed to verify the hypotheses of this research. In level 1 model, control variables of the number of employees, the firm size, the industrial scale, the industrial maturity, and the degree of competition were measured; level 2 model measured independent variables of Acquisition / Internalization, technological exploitation, market exploitation; level 3 model measured a moderating variable of open innovation; and in level 4 model, to evaluate the interaction between independent and moderating variables, new interacting variables were created and measured by multiplying sub-factors of each independent variable by sub-factors of each moderating variable.

The above table, which the results of hierarchical regression analysis of each variable for financial performance, shows that the number of employees, the firm size, the industrial scale, the industrial maturity, and the degree of competition all had no significant relations with financial performance in level 1 model.

Table 2. Hierarchical Regression Analysis -1

\begin{tabular}{|c|c|c|c|c|}
\hline Dependent variable & Financial perfo & ance & & \\
\hline Variable & model 1 & model 2 & model 3 & model 4 \\
\hline \multicolumn{5}{|l|}{ Stage 1: control variable } \\
\hline Firm size & $.042(.317)$ & $-.306(-.961)$ & $-.039(-1.387)$ & $-0.43(-1.450)$ \\
\hline Number of employee & $-.080(-.523)$ & $-.083(-1.887)$ & $-.012(-.343)$ & $-.016(-.458)$ \\
\hline Industry size & $-.165(-1.216)$ & $-.010(-.234)$ & $.048(1.495)$ & $.045(1.411)$ \\
\hline Industry maturity & $.239(1.473)$ & $.115(2.487)^{* *}$ & $.040(1.087)$ & $.030(.789)$ \\
\hline Degree of competition & $-.092(-.666)$ & $.100(2.428)^{* *}$ & $-.042(-1.113)$ & $-.042(-1.111)$ \\
\hline \multicolumn{5}{|l|}{ Stage 2: Independent variable } \\
\hline Acquisition/Internalization & & $.219(3.858)^{* * *}$ & $.332(7.073)^{* * *}$ & $.202(.952)$ \\
\hline Technological exploitation & & $.431(7.213)^{* * *}$ & $.354(7.610)^{* * *}$ & $.684(3.255)^{* * *}$ \\
\hline Market exploitation & & $.449(9.209)^{* * *}$ & $.315(-2.669)^{* * *}$ & $.463(-2.865)^{* * *}$ \\
\hline \multicolumn{5}{|l|}{ Stage 3: moderated variable } \\
\hline Open innovation & & & $.760(6.808)^{* * *}$ & $.639(3.468)^{* * *}$ \\
\hline \multicolumn{5}{|l|}{ Stage 4: moderated effects } \\
\hline $\begin{array}{l}\text { Acquisition/Internalization } \times \text { Open } \\
\text { innovation }\end{array}$ & & & & $.195(.553)$ \\
\hline $\begin{array}{l}\text { Technological exploitation } \times \text { open } \\
\text { innovation }\end{array}$ & & & & $.537(-1.635)$ \\
\hline Market exploitation $\times$ open innovation & & & & $.429(1.635)$ \\
\hline$R^{2}$ & 0.48 & .928 & .959 & .962 \\
\hline$\Delta R^{2}$ & .048 & .880 & .032 & .003 \\
\hline Adjusted $R^{2}$ & -.028 & .918 & .953 & .954 \\
\hline$F$ & .633 & $96.012 * * *$ & $155.006^{* * *}$ & 119.179 \\
\hline$\Delta F$ & .633 & $242.830 * * *$ & $46.354 * * *$ & $1.434 * * *$ \\
\hline
\end{tabular}

t-value $p^{*}<.1, p^{* *}<.05, p^{* * *}<.01,(\mathrm{n}=69)$ 
Table 3. Hierarchical Regression Analysis -2

\begin{tabular}{|c|c|c|c|c|}
\hline \multirow{2}{*}{$\begin{array}{l}\text { Dependent variable } \\
\text { Variable }\end{array}$} & \multicolumn{4}{|c|}{ Innovation performance } \\
\hline & model 1 & model 2 & model 3 & model 4 \\
\hline \multicolumn{5}{|l|}{ Stage 1: control variable } \\
\hline Firm size & $.031(.233)$ & $-.051(-1.303)$ & $-.054(-1.749)^{*}$ & $-.056(-1.797)^{*}$ \\
\hline Number of employee & $-.079(-.518)$ & $-.087(-1.916)$ & $-.018(-.487)$ & $-.026(-.690)$ \\
\hline Industry size & $-.169(-1.246)$ & $-.016(-.377)$ & $.039(1.144)$ & $.034(1.002)$ \\
\hline Industry maturity & $.235(1.447)$ & $.113(2.378)^{* *}$ & $.041(1.032)$ & $.035(.853)$ \\
\hline Degree of competition & $-.091(-.655)$ & $.107(2.533)^{* *}$ & $-.029(-.722)$ & $-.028(.853)$ \\
\hline \multicolumn{5}{|l|}{ Stage 2: Independent variable } \\
\hline Acquisition/Internalization & & $.200(3.428)^{* * *}$ & $.299(6.103)^{* * *}$ & $.271(1.196)$ \\
\hline Technological exploitation & & $.422(6.872)^{* * *}$ & $.348(6.948)^{* * *}$ & $.677(3.023)^{* * *}$ \\
\hline Market exploitation & & $.474(9.476)^{* * *}$ & $.260(2.049)^{* *}$ & $.481(2.791)^{* * *}$ \\
\hline \multicolumn{5}{|l|}{ Stage 3: moderated variable } \\
\hline Open innovation & & & $.731(6.086)^{* * *}$ & $.625(3.186)^{* * *}$ \\
\hline \multicolumn{5}{|l|}{ Stage 4: moderated effects } \\
\hline $\begin{array}{l}\text { Acquisition/Internalization } \\
\text { Open innovation }\end{array}$ & & & & $.038(.100)$ \\
\hline $\begin{array}{l}\text { Technological exploitation } \times \\
\text { open innovation }\end{array}$ & & & & $.579(2.069)^{* *}$ \\
\hline $\begin{array}{l}\text { Market exploitation } \times \text { open } \\
\text { innovation }\end{array}$ & & & & $.543(-1.550)$ \\
\hline$R^{2}$ & .047 & .923 & .953 & .957 \\
\hline$\Delta R^{2}$ & .047 & .877 & .030 & .004 \\
\hline Adjusted $R^{2}$ & -.029 & .913 & .946 & .948 \\
\hline$F$ & .620 & $90.449 * *$ & $122.809 * *$ & 104.285 \\
\hline$\Delta F$ & .620 & $228.943 * * *$ & $37.041 * * *$ & $1.833^{* * *}$ \\
\hline
\end{tabular}

t-value $p^{*}<.1, p^{* *}<.05, p^{* * *}<.01,(\mathrm{n}=69)$

Model 2 presented the verification of hypothesis 1 and its specific hypotheses, and the model of level 2, which evaluated the relations between management performance and independent variables, proved suitable in the model $\left(\mathrm{R}^{2}=.928, \Delta \mathrm{F}=242.830, \mathrm{p}<.01\right)$. Regarding specific factors of Model 2 , Acquisition / Internalization $(\beta=.219, \mathrm{p}<.01)$ had a significant effect on financial performance positively $(+)$, and technological exploitation $(\beta=.431, \mathrm{p}<.01)$ and market exploitation $(\beta=.449, \mathrm{p}<.01)$ had strong positive $(+)$ effects on financial performance as well. Model 3 verified the influence of the moderating variable of open innovation on management performance, which showed a significant effect of open innovation $(\beta=.7609, \mathrm{p}<.01)$ in a positive $(+)$ manner.

The suitability of Model 3 proved suitable with regard to model fit $\left(\mathrm{R}^{2}=.959, \Delta \mathrm{F}=46.354, \mathrm{p}<.01\right)$. However, level 4 model to verify the moderating effect of open innovation showed that each independent variable and items of interaction did not influence financial performance significantly. 
The results of hierarchical regression analysis of each variable for innovation performance are shown in the table below, which reveals that the number of employees, the firm size, the industrial scale, the industrial maturity, and the degree of competition did not have any significant

Correlations with financial performance. Model 2 presented the verification of hypothesis 1 and its specific hypotheses, and the model of level 2, which evaluated the relations between management performance and independent variables, proved suitable in model fit $\left(\mathrm{R}^{2}=.923, \Delta \mathrm{F}=228.943, \mathrm{p}<.01\right)$.

Regarding specific factors of Model 2 Acquisition / Internalization $(\beta=.200, p<.01)$ had a significant effect on financial performance positively $(+)$, and technological exploitation $(\beta=.422, p<.01)$ and market exploitation $(\beta=.474$, $\mathrm{p}<.01)$ had strong positive $(+)$ effects on financial performance as well. Model 3 verified the influence of the moderating variable of open innovation on management performance, which showed a significant effect of open innovation $(\beta=.731, \mathrm{p}<.01)$ in a positive $(+)$ manner.

In Model 4 to verify the moderating effect of open innovation, we verified its effect on innovation performance using the values of interaction items for each independent and moderating variable, which showed that only the interaction item of technological exploitation and open innovation $(\beta=.579, \mathrm{p}<.05)$ had a strong effect on innovation performance positively.

\section{Conclusions}

This research investigated the relations between factors in the process of commercializing transferred technology and a firm's financial and innovation performances. Previous studies claim that firms faced with ever changing environment should not emphasize only one dimension between the two extremes of exploratory innovation and exploitational innovation in strategic importance, but should combine concurrency and Ambidexterity and achieve innovation in relevant proportion by considering external context and internal factors the firm face.

So for small and medium-sized firms that have limited funds and manpower to invest in their technology innovation, they are forced to focus on exploitational innovation of the existing technology and products in order to maximize their profits and expand their market share, but they cannot but consider exploratory innovation in aspects of competitive advantage and growth through acquisition of new markets (Benner \& Tusuman, 2003; Katila \& Ahuja, 2002; Lee et al., 2003; Nerkar, 2003; S. Park \& B. Lee, 2008).

To solve these problems, small and medium-sized firms in Korea are working out strategies to maintain the existing markets as well as to tap into new markets by adopting new technologies through industry-academy-institute cooperation and transfer. And they are carrying out open innovation to make up for the drawbacks coming from geographic proximity to industrial complexes and clusters and to innovate techniques organizationally.

Therefore, this research classified the firms' internal capability factors into Acquisition / Internalization, technological exploitation, and market exploitation capabilities so as to examine internal capability, financial performance and innovation performance of small and medium-sized firms which adopt technologies; investigated which factor has strong influence on its relations with financial and innovation performances; and evaluate the moderating effect of open innovation as a factor to intensify the relations.

The empirical analysis results of the research are as follows:

First, we found that acquisition/internalization affected greatgly the firm's financial performance and innovation performance (the speed of commercialization, the number of new product developments), This is because the firm produces and sells the products by immediately using its transferred technology or modifying the technology a little, which influences strongly the firm's short-term sales. Moreover, the accumulated experience with acquisition/internalization of the transferred technology reduces time and physical costs of work forces in its secondary production process, which leads to the improved producing speed, and has the firm make techniques to complement the drawbacks of the existing goods, which stimulates the development of new technology and new products.

Second, technological exploitation has positive effects on on their financial performance and innovation performance (the speed of commercialization, and the number of new product developments). It indicates that they concentrate on manufacture and production using the adopted technology to increase their immediate sales. This situation is well presented in a series of process, during which they are centering on the short-term profits, the characteristic of small and medium-sized firms, and they produce the products by making use of the existing technology rather than brand new technology, sell them to their already positioned market, and increase sales of them.

Third, market exploitation also influenced strongly financial and innovative performances. This is because small and 
medium-sized companies in Korea produce and deliver products that higher level companies order rather than they develop their own products and improve the management performance by selling them to the market. Also manufacturing, production, and marketing capabilities, which are the sub-variables of market exploitation capability, exert their impacts on improvement of business competition, which does, in turn, important work in financial and innovation performances.

Fourth, small and medium-sized firms seek to overcome the drawbacks coming from geographic proximity by means of open innovation during the process of commercializing the goods with their transferred techniques. The result of verifying the moderating effects of open innovation showed that it did not moderate financial performance, and it moderated only technological exploitation regarding internal capability factors and innovation performance.

The results directly reflect the current situation of small and medium-sized companies, and through open innovation, they are trying to raise their business efficiency by increasing the speed of producing their main products and also trying to acquire know-hows of processing innovation necessary for developing new products from external sources in order to overcome the limitations of developing on their own. Nevertheless, the fact that they do not create profits by applying technology and know-hows acquired from open innovation to commercializing new products and enhancing productivity of main products through R\&D means that they lacks the capability to use the technology and know-hows.

\subsection{Implications}

What this research implies in the aspects of company operation, policies and studies as follows:

First, regarding company operation, the firm's financial performance affects greatly Acquisition / Internalization, technological exploitation, and market exploitation of the transferred techniques, and so to improve its financial performance by commercializing the adopted technology, it should distribute investment to overall parts. The speed of technology commercialization, the innovative outcome of transferred technology commercialization, can be achieved by open innovation, but the firm should increase its general capabilities to continue this outcome toward the firm's financial performance. If the firm concentrate on investing R\&D and production/process capabilities that are directly related with production and manufacturing, it will bring about continuous competitive edge and acquisition of new markets.

Second, considering the academic aspect, there are few studies on technology commercialization through technology transfer from the viewpoint of innovators. This research has a significance in that it provided an overall blueprint for commercializing adopted technology by modifying and verifying the process of adopted technology commercialization according to introduction technique commercialization. And we identified influence factors of adopted technology commercialization from the innovator's viewpoint. We organized influence factors like this: we extracted the factors affecting the firm's performance from learning and internalization, exploitational innovation, industrialization capabilities and took them as sub-factors of variables for Acquisition / Internalization, technological exploitation, and market exploitation capabilities that were newly generated.

\subsection{Limitations}

First, we had difficulties selecting performances and influence factor variables as there were not sufficient theories from previous studies and the existing research, which means the limitations for adopting and measuring influence factors. This study did not analyze company information using objective indicators of the company, but analyzed collected company information from the survey targeting persons in charge of firms' commercializing adopted technology. At this point, we surveyed persons in charge of technology transfer commercialization as their job, but the survey questions requiring specialized knowledge of the respondents leave a lot to be desired in the reliability.

Second, due to the difficulties of collecting data, we divided business performance into financial performance and innovation performance and measured them. The results of the survey targeting firms that had experienced technology transfer showed that there were wide variations in the item of the number of new product developments depending on the firms' characteristics, and so we divided them in interval(7 section) and measured them. In addition, there appeared figures in the comparison item with competitors, which indicated respondents' subjective judgments were involved. So we measured only the total sales, the speed of technology commercialization, and the number of new product developments when assessing financial and innovation performance. To evaluate business performances more accurately, measurement should be conducted with various items targeting various parts in the further studies. 


\section{References}

Bae, J.T. (1997). Relationships between Technological Cooperation Activities and Performance of Small and Medium sized Companies in Korea. The Korean Association of Small Business Studies, 19(2), 273-296.

Benner, M.J., \& Tushmans, M.L. (2003). Exploitation, Exploration, and Process Management: The Productivity Dilemma Revisited. The Academy of Management Review, 28, 238-256.

Bhave, M.P. (1994). A Process of Entrepreneur Venture Creation. Journal of Business Venturing, 10(3), $223-242$. http://dx.doi.org/10.1016/0883-9026(94)90031-0

Carayannis, E.G., \& Alexander, J. (2002). Is Technological Learning a Firm Core Competence, When, How and Why? A Longitudinal, Multi-Industry Study of Firm's Technological Learning and Market Performance. Technovation, 22(10). http://dx.doi.org/10.1016/S0166-4972(01)00047-5

Carr, R.K. (1992). Doing Technology Transfer in Federal Laboratories. Journal of Technology Transfer, 17. http://dx.doi.org/10.1007/BF02199474

Chen, J., \& Qu, W.G. (2003). A New Technologycal Learning in China. Technovation, 23. http://dx.doi.org/10.1016/S0166-4972(02)00038-X

Chesbrough, H. (2003). The Era of Open Innovation. Mit Sloan Management Review, 35-41.

Chesbrough, H. (2004). Open Innovation. Research Technology Management.

Chesbrough, H. (2006). Open Innovation: The New Imperative For Creating and Profiting From Technology. HBS Press.

Chesbrough, H. (2007). Open Innovation and Strategy. California Management Reviews, 50(1), 57-76. http://dx.doi.org/10.2307/41166416

Chesbrough, H., \& Adrienne, K.C. (2006). Beyond high tech: early adopters of open innovation in other industries. $R \& D$ Management, 36(3), 229-236. http://dx.doi.org/10.1111/j.1467-9310.2006.00428.x

Choi, Y., \& Lee, J. (2000). Success Factor for Transferring Technology to Spin-off Application: The Case of Technology Property Rights Concession Program in Korea. Journal of Technology Transfer, 25, $237-246$. http://dx.doi.org/10.1023/A:1007889010655

Daghfous, A. (2003). An Empirical Investigations of the Roles of Prior Knowledge and Learning Activities in Technology Transfer. Technovation, 24, 939-953. http://dx.doi.org/10.1016/S0166-4972(03)00059-2

Dyer, J.H., \& Hatch, N.W. (2006). Relation-spcific capabilities and barriers to knowledge transfer: Creating advantage through network relationships. Strategic Management Journal, 27, 710-719. http://dx.doi.org/10.1002/smj.543

Evan, W., \& Olk, P. (1992). Transferring Technology in R\&D Consoria: Effective Forms of Inter-Organization Relations in Technology Transfer in Consoritia and Strategies alliances. Rowman \& Littlefield Publishers, Inc.

Floyd, C. (1997). Managing Technology for Corporate Success. Gower, Hampshire.

Gerpott, T.J. (2005). Strategisches Technologie- und Innovation Management. Stuttgart.

Gibson, D.V., \& Smilor, R.W. (1991). Key Variable in Technology Transfer: A Field Study Based Empirical Analysis. Journal of Engineering and Technology Management, 38. http://dx.doi.org/10.1016/0923-4748(91)90015-J

Ginner, M.A., \& Franza, R.M. (2003). Barriers and Bridges for successful Enviromental Technology Transfer. Journal of Technology Transfer, 28, 167-177. http://dx.doi.org/10.1023/A:1022998617118

Griffin, A., \& Hauser, J.R. (1996). Integrating R\&D and Marketing: a review and analysis of the literature. Journal of Product Innovation Management, 13, 191-215. http://dx.doi.org/10.1111/1540-5885.1330191

Ha, S.U. (2010). Impact of Exploitation and Exploration on the Firm Performance. The Korean Academic Society of Business Administration, 39(4), 907-937.

He, Z.L., \& Wong, P.K. (2004). Exploration ang Exploitation : An Empirical Test of Ambidextrity Hypothesis. Organization Scirnce, 15(4), 481-494. http://dx.doi.org/10.1287/orsc.1040.0078

Im, C.M., \& Yang, D.W. (2008). Comparative Study on the University Technology Transfer Performance by Royalty Incentive Systems. The Korean Association of Small Business Studies, 11(3), 83-102. 
Im, C.M., \& Yang, D.W. (2009). The Comparative Study on the University Technology Transfer Performance by Royalty Incentive Systems. Korean Academic Society of Business Administration, 22(2), 889-912.

Jansen, J.J.P., Van Den Bosch, F.A.J., \& Volberda, H.W. (2005). Managing potential and realized absorptive capacity: How do organizational antecedents matter? Academy of Management Journal, 48(6), 999-1015. http://dx.doi.org/10.5465/AMJ.2005.19573106

Jolly, V.K. (1997). Commercializaing New Technologies. Havard Business School Press, Boston, MA.

Katila, R., \& Ahuja, G. (2002). Something Old, Something New: A Longitudinal Study of Serch Brhavior and New Product Development. Academy of Management Journal, 45, 1183-1194. http://dx.doi.org/10.2307/3069433

Khalil, T. (2000). Management of Technology: The Key of to Competitiveness and Wealth Creation. McGraw-Hill, Singapore.

Kim, G.D., et al. (1991). A study on the promotional Measures for the Commercialization of the Research Results. Korean Institute for Industrial Economics and Technology.

Kim, K.H., \& Hyun, S.H. (2006). Effects of Institutional Environments and Strategic Resources of University TLOs on Technology Commercialization. The Korean Association of Small Business Studies, 9(1), 87-109.

Kim, S.H., \& Kim, J.H. (2008). A Performance of Open Technology Innovation by Industry: Moderating Effect of Involvement and Commitment. Korean production \& operation management society, 19(3), 21-49.

Kwon, G.J., \& Noh, M.J. (2007). A Study on the Analysis of Small Business Technology Transfer Problems and the Suggestion of Technology Transfer Promotion Method in Daegu City. International Area Studies Review, 11(1), 656-682.

Lall, S. (1985). Multinationals Technology and Experts. New York. ST.martain's Press, p.132.

Lane, P.J., \& Lubutkin, M. (1997). Relative Absorptive Capacity and Inter-Organizational Learning. Strategic Management Journal, 19, 461-477.

Lasserre, P. (1982). Training: Key to Technological Transfer. Long Range Planning, 15(3), 51-60. http://dx.doi.org/10.1016/0024-6301(82)90026-7

Lee, D.M., \& Lim, S.J. (2009). Determinants of Exploitative \& Exploratory Innovation Activities and Their Effects on Innovation Output and Perceived Performance. Journal of Strategic Management, 15(1).

Lee, D.S., \& Chung, L.C. (2010). A Study on the Effect of Technological Innovation Capability and Technology Commercialization Capability on Business Performance in SMEs of Korea. The Korean Association of Small Business Studies, 32(1), 65-87.

Lee, S.H., \& Lee, C.L. (2010). Openness, Technology Transfer and Economic Growth. Journal of International Trade and Industry Studies, 15(1), 27-55.

Lee, S.K., et al. (2005). A Study on Technology Transfer Performances and Its Determinants of Technology Licensing Organization. The Korean regional development association, 17(3), 31-50.

Lee, S.W., et al. (2007). A Study on Stages of Internal Technology Transfer between Headquarter and Division in a Global Firm. Korean Academic Society of Business Administration.

Lee, Y.D. (2004). Success Factors of Commercialization in IT Technology. Journal of Technology Innovation, 12(3), 259-276.

Levinthal, D.A., \& March, J.G. (1993). The Myopia of Learning. Strategic Management Journal, 14, 95-112. http://dx.doi.org/10.1002/smj.4250141009

Lichtenthaler, U. (2009). Absorptive capacity, environmental turbulence, and the complementarity of Organizational learning processes. Academy of Management Journal, 52(4), 822-846. http://dx.doi.org/10.5465/AMJ.2009.43670902

Lin, C.H., Chang, S.F., \& Chang, C.S. (2004). The Impact of Technology Absortive Capacity on Technology Transfer Performance. International Journal of Technology Transfer and Commercialization, 3(4), 384-409. http://dx.doi.org/10.1504/IJTTC.2004.005610

Lindert, P.H., \& Kindleberger, C.P. (1982). International Economics 7Th. Homewood, Richard D. Irwin, pp.65-68.

Mansfield, E. (1988). The Speed and Cost of Industrial Innovation in Japan and The United State: External vs Internal Technology. Management Science, 34(10), 157-168. http://dx.doi.org/10.1287/mnsc.34.10.1157 
March, J.G. (1991). Exploration ang Exploitation in Organozation Learning. Organization Science, 2(1), 71-87. http://dx.doi.org/10.1287/orsc.2.1.71

Naruemon \& Whangthomkun. (2006). An Empirical From a Case Study. Policy Studies Journal, (22).

Nerkar, A. (2003). Old is Good? The Value of Temporal Exploration in the Creation of New Knowledgy. Management Science, 49, 211-229. http://dx.doi.org/10.1287/mnsc.49.2.211.12747

Nevens, T.M., Summe, G.L., \& Uttal, B. (1990, May-June). Commercializing technology; what the best companies do? Harvard Business Review, 154-163. http://dx.doi.org/10.1108/eb054310

Park, H.J., et al. (2006). An Analysis of Effective Factors for Defense Technology Transfer. Military Operations Research Society of Korea, 32(1), 1-12.

Park, J.H. (2007). Development and Application of Checklist for the Evaluation of International Technology Transfer: From the Viewpoint of Licensor. Korean-German academy of economics and management. 26(2), 58-82.

Park, S.C. (2007). Study on the model of effective technology transfer among companies in both Korea and China. International Area Studies Review.

Park, S.M., \& Lee, B.H. (2008). The Impact of Exploration, Exploitation, and R\&D Organization on Innovations in the Korean SMEs. Korea technology innovation society, 11(1), 118-143.

Prahalad \& Hamel. (1990, May-June). The Core Competencies of Corporation. Harvard Business Review, 68(3), 79-91.

Reddy, A.M., \& Zhao, L. (1990). International Technology Transfer: A Review. Research Policy, 19, 285-307.

Russo, J., \& Hweenwnkohl, R.C. (1990). Factor Affection the Transfer of Technology from Industry/University Cooperative to Sponsoring Companies. Technology Transfer, Summer, 21-28.

Santoro, M.D., \& Chakrabarti, A.K. (2002). Firm Siza and Technology Centrality in Industry-University Interactions. Research Policy, 31. http://dx.doi.org/10.1016/S0048-7333(01)00190-1

Schroeder, R.G., Bates, K.A., \& Junttila, M.A. (2002, Febrary). A Resource-basedview of manufacturing strategy and the relationship to manufacturing performance. Strategic Management Journal, 23(29), 105-117. http://dx.doi.org/10.1002/smj.213

Seo, Y.H., \& Yang, D.W. (2007). The Empirical Study on Relationship between Technology Factor and Tech. Commercialization in CT SMEs and Ventures. Korea technology innovation society, 15(1).

Sohn, S.Y., \& So, H.K. (2002). Effective Commercialization Strategies for the RD in the Area of Information Communication Technology. Journal of the Korean Institute of Industrial Engineers, 28(2), 201-215.

Soulder, W.E. (1990). A Guide to the Best Technology Transfer Pactices. Journal of Technology Transfer, 15.

Spann, M.S., Adams, M., \& Souder, W.E. (1993). Improving Federal Technology Commercialization: some Recimmendations from s Field Study. Journal of Technology Transfer, 28.

Yam, R.C.M., Guan, J.C., Pun, K.F., \& Tang, E.O. (2004). An Audit of Technological Innovation Capabilities in Chinese Firms: Some Empirical Findings in Beiling, China. Research Polocy, 31(3), 543-567.

Yap, C.M., \& Souder, W.E. (1994). Factors Influencing New Product Success and Failure in Small Entrepreneurial High-Technology Electronics Firm. Joural of Product Innovation Managrment, 11(5), 418-432.

Yun, J.H., \& Choi, M.S. (2008). Comparative Study of the Open innovation and Performance of firms. The Korean Association for Policy Studies, 17(4), 163-191.

Yun, J.H., \& Ryu, G.W. (2009). A preliminary study on the theory and phenomena of Korea Open Innovation. Korea Association for International Commerce and Information, 11(2), 203-230.

Zahara, S.A., \& Bogner, W.C. (2000). Technlogy Strategy and Soft-ware New entures Performence-A Study of Coporate-spoon and Independent Biotechnology Ventures. Journal of Business Venturing, 15(2), 135-173.

Zahra, S.A., \& Nielsen, A.P. (2002). Sources of capabilities, integration and technology commercialization. Strategic Management Journal, 23. http://dx.doi.org/10.1002/smj.229

Zhao, L., \& Reddy, N. (1993). Managing International Technology Transfer Negotiation: A Social Exchange Perspective. Technovation, 13(6), 383-397. http://dx.doi.org/10.1016/0166-4972(93)90078-A 